\title{
Duodenal ulcer is associated with low dietary linoleic acid intake
}

\author{
H W Grant, K R Palmer, R R Riermesma, M F Oliver
}

\begin{abstract}
It has been suggested that the falling incidence and virulence of duodenal ulcer is related to increased dietary polyunsaturated essential fatty acid intake. The adipose fatty acid profile, which closely reflects dietary intake, was measured in 35 men with chronic duodenal ulcer and 35 matched control men. The mean percentage of linoleic acid in adipose tissue was significantly lower in the ulcer group (10.0 $(0.7) v 12.3(0.7) \%, p<0.01)$ and this difference was found in both smokers and non-smokers. This finding suggests that the diets of duodenal ulcer patients are deficient in linoleic acid and this could be of aetiological importance.
\end{abstract}

Over the past 30 years the incidence and virulence of peptic ulcer have fallen in the West. ${ }^{1}$ This cannot be explained by the use of powerful ulcer healing drugs because these have been developed only relatively recently; nor is it likely to be caused by changes in smoking or alcohol consumption. Hollander and Tarnawski ${ }^{2}$ have suggested that alterations in the dietary consumption of polyunsaturated essential fatty acids could modify the natural history of peptic ulcer; they noted that the mean per capita consumption of linoleic acid has increased by at least $200 \%$ at the same time as mortality from peptic ulcer has decreased by more than $50 \%$.

Linoleic acid is the most important dietary precurser of prostaglandins and in previous experiments we showed that in healthy men, modest amounts of dietary linoleic acid greatly increased gastric prostaglandin $\mathbf{E}$ secretion and suppressed gastric acid output. ${ }^{3}$ Exogenously administered prostaglandins are known to decrease gastric acid secretion ${ }^{4}$ and enhance mucosal protective mechanisms. ${ }^{5}$ This paper explores the hypothesis that the diet of duodenal ulcer patients is relatively deficient in linoleic acid. This leads to decreased endogenous gastric prostaglandin secretion, and the consequent increase in acid secretion and impairment of mucosal defence mechanisms predispose to ulcer formation.

Although it is possible to measure accurately dietary linoleic consumption, this is laborious and unreliable because the linoleic acid content of many common foods in unknown and dietary recall is poor. The adipose fatty acid profile closely reflects dietary fat intake over the preceding nine to 12 months, however, and has been used in case control studies of fatty acids and ischaemic heart disease. ${ }^{6}$ We have therefore measured the adipose fatty acid profile of men with duodenal ulcer and matched control subjects.
Methods

SUBJECTS

Thirty five men aged between 21 and 79 years (median 45 years) with endoscopically proved chronic duodenal ulcers were studied. All of these men had a long history of dyspepsia but none had undergone ulcer surgery or was taking non-steroidal anti-inflammatory drugs, histamine receptor antagonists, or prostaglandin analogues at the time of the study. Each ulcer patient was matched with a control subject of similar age, social class, and smoking history. The control subjects comprised patients undergoing routine minor elective surgery (principally inguinal hernia repair and haemorrhoidectomy) and laboratory personnel. None had a history of dyspepsia or was taking any drugs. Their ages ranged from 18 to 75 years (median 46 years). Non-smoking was defined as never having smoked or having stopped for at least six months before the study; current smokers were matched for their daily cigarette consumption.

\section{ADIPOSE TISSUE SAMPLING AND FATTY ACID} ANALYSIS

Approximately $20 \mathrm{mg}$ of subcutaneous adipose tissue were obtained under local anaesthetic from the anterior abdominal wall using a $3 \mathrm{~mm}$ diameter Stieffel needle. The fat was separated from the skin, dried on absorbant paper, and stored at $-60^{\circ} \mathrm{C}$. The fatty acid profile was determined using a previously described chromatographic method. ${ }^{6}$ Briefly, this involves extraction into heptane, removal of nonoesterified fatty acids and phospholipids with isopropanol, followed by methylation and chromatography on a GP $10 \%$ GP-2330 packed 100/120 mesh chromosorb column. The peaks were identified using a flame ionisation detector. Results are expressed as relative percentages.

Ethical permission was obtained from the Lothian Ethics of Medical Research SubCommittee for Medicine and Clinical Oncology, and subjects gave informed consent.

\section{STATISTICAL METHODS}

Differences between the percentages of fatty acids were determined using the Student's $t$ test.

\section{Results}

Adipose tissue was obtained from all subjects without causing appreciable discomfort and no complications resulted from the biopsy technique.

The adipose fatty acid profiles of the ulcer and control subjects are shown in Table I. Values for 
TABLE I Mean (SD) values of adipose tissue fatty acid (\% composition $w / w)$

\begin{tabular}{lcc}
\hline Fatty acid & Healthy controls & $\begin{array}{l}\text { Duodenal ulcer } \\
\text { patients }\end{array}$ \\
\hline Palmitic & $22 \cdot 7(5 \cdot 55)$ & $21 \cdot 9(0 \cdot 34)$ \\
Palmitoleic & $6 \cdot 1(0 \cdot 28)$ & $7 \cdot 9(0 \cdot 28)$ \\
Stearic & $4 \cdot 8(0 \cdot 26)$ & $4 \cdot 0(0 \cdot 16)$ \\
Oleic & $47 \cdot 1(0 \cdot 48)$ & $47 \cdot 7(0 \cdot 78)$ \\
Linoleic $^{\star}$ & $12 \cdot 3(0 \cdot 75)$ & $9 \cdot 9(0 \cdot 68)$ \\
Minor fatty acids $(\mathrm{n}=21)$ & $7 \cdot 0(0.60)$ & $8 \cdot 5(0 \cdot 42)$ \\
\hline
\end{tabular}

${ }^{\star} \mathrm{p}<0 \cdot 01$.

TABLE II Mean (SD) adipose 5 linoleic acid in smokers and non-smokers

\begin{tabular}{|c|c|c|c|}
\hline & All subjects & Smokers & Non-smokers \\
\hline $\begin{array}{l}\text { No of duodenal ulcer } \\
\text { subjects } \\
\% \text { Linoleic acid } \\
\text { No of healthy controls } \\
\text { \% Linoleic acid }\end{array}$ & $\begin{array}{l}35 \\
9.9(0.68) \\
35 \\
12 \cdot 3(0.75)^{\star}\end{array}$ & $\begin{array}{l}19 \\
9 \cdot 4(0.59) \\
14 \\
12 \cdot 1(0.85)^{\star}\end{array}$ & $\begin{array}{l}16 \\
10 \cdot 8(0 \cdot 72) \\
21 \\
12 \cdot 4(0.93)^{\star}\end{array}$ \\
\hline
\end{tabular}

$\star$ Ulcers $v$ controls. $\mathrm{p}<0 \cdot 01$.

the major fatty acids are shown; those for the remaining 21 minor acids are summarised as minor fatty acids. Values differed significantly only in respect of the percentage of linoleic acid and were significantly lower in the ulcer group. This was true for smokers and non-smokers (Table II). In contrast to the results of Wood et $a l,{ }^{6}$ within the two groups, the percentage of linoleic acid in adipose tissue was similar in smokers and non-smokers.

\section{Discussion}

The study has shown that mean dietary linoleic acid intake was lower in male duodenal ulcer patients than in control subjects of similar age, smoking habits, and social class. These findings and our previously reported observations that linoleic acid ingestion increased gastric prostaglandin secretion and decreased acid output are consistent with the hypothesis that dietary essential fatty acids influence the natural history of duodenal ulcer. The alternative interpretation that ulcer patients have an aversion to linoleic acid - seems unlikely, particularly since medicines containing essential fatty acids may relieve dyspepsia.
A longitudinal study, in which serial measurements of adipose fatty acid profile would be related to exacerbations and remissions of ulcer disease, would be necessary to provide more information about this relation. This would be practically difficult and may not conclusively support an association rather than aetiological link.

We believe it likely that the postulated effects of linoleic acid upon duodenal ulcer are mediated through changes in gastroduodenal prostaglandin metabolism. Experiments in animals ${ }^{78}$ and $\operatorname{man}^{3}$ have shown that the availability of dietary polyunsaturated fatty acids influences prostaglandin E output in gastric juice, acid secretion, and mucosal protection against a range of damaging materials. In a previous study we showed that in normal subjects dietary linoleic acid increased gastric prostaglandin secretion and suppressed acid output, but this did not occur in patients with duodenal ulcer. ${ }^{9}$ It may therefore be that normal subjects protect their gastric mucosa by consuming essential fatty acids while this does not occur in duodenal ulcer because these patients do not respond to dietary linoleic acid by increasing gastric prostaglandin secretion.

1 Coggan D, Lambert P, Langman MJS. 20 years of hospital admissions for peptic ulcer in England and Wales. Lancet 1981 ; i: $1302-4$.

2 Hollander D, Tarnawski A. Dietary essential fatty acids and the decline in peptic ulcer disease - a hypothesis. Gut 1986; 27 : 239-42.

3 Grant HW, Palmer KR, Kelly RW, Misiewicz JJ. Dietary linoleic acid, gastric acid and prostaglandin secretion. Gastroenterology 1988; 94: 955-9.

4 Robert A, Nylanda B, Anderson S. Marked inhibition of gastric secretion by two prostaglandin analogues given orally to man. Life Sci 1974; 14: 533-8.

5 Robert A, Nezamis JE, Lancaster C, Hanchar AJ. Cytoprotection of prostaglandin in rats. Prevention of gastric necrosis produced by alcohol, $\mathrm{Hcl}, \mathrm{Na} \mathrm{OH}$, hypertonic $\mathrm{NaCl}$ and produced by alcohol, Hcl, Na OH, hypertonic
thermal injury. Gastroenterology 1979; 77: 433-43.

6 thermal injury. Gastroenterology 1979; 77: 433-43. MacIntyre C, Elton RA, Oliver MF. Linoleic acid and eicosapentaenoic acids in adipose tissue and platelets and risk of coronary heart disease. Lancet 1987; i: 177-82.

7 Hollander D, Tarnawski A, Ivey KJ, De Zeerey A, et al. Arachidonic acid protection of rat gastric mucosa against alcohol. F Lab Clin Med 1982; 100: 296-308.

8 Schepp W, Steffan B, Ruff HJ, Schusdiarra, et al. Modulation of rat gastric mucosal prostaglandin $E_{2}$ release by dietary linoleic acid; Effect on gastric acid secretion and stress

9 Grant HW, Palmer KR, Kelly R, Misiewicz JJ. Failure of endogenous PGE secretion in duodenal ulcer. Gut 1988; 29: A709. 